\title{
Mengembangkan Kelompok Pemusik Melalui Relief Tentang Musik di Candi Borobudur
}

\author{
Widya Nayati \\ Departemen Arkeologi, Fakultas Ilmu Budaya, Universitas Gadjah Mada \\ Pos-el: widyanayati@ugm.ac.id
}

Tim Pengabdian kepada Masyarakat:

Widya Nayati, Bramantara, Nurkotimah, Rina Yulianti, Sita Nurwardiyati, Agustinus

Wisnu K., M. Nofri Fahrozi, dan Gendro Keling.

\begin{abstract}
Learning can be done by anyone and anywhere. Cultural heritage provides an alternative interesting learning resource. It is just that not many people understand the benefits that can be obtained from cultural heritage. This Community Service by FIB UGM in 2018 made an effort so that people would be more familiar with learning resources from cultural heritage objects. The objects used in this study are reliefs which depict a music group from the Borobudur Temple. This choice is based on Gardner's theory which states that every human being has a different intelligence. Among the nine intelligences presented by Gardner, musical intelligence is one of them. By applying Gardner's theory, especially musical intelligence, the introduction of objects of relief about people playing music from Borobudur reliefs to people who like music is expected to be able to facilitate them to capture the message conveyed.

Reliefs about people playing music from Borobudur Temple is introduced to a group of musicians, namely the Pesantian Wisnu Sakti Tambakan group located in Tambakan Village, Jogonalan District, Klaten Regency. The way to do this is to look at and imitate body movements such as those depicted on the reliefs of musicians playing musical instruments at Borobudur Temple. The result of the observations show that the participants feel the beauty of the movements and feel the sound of the music produced with the position of the hands and the appropriate instruments so as to produce beautiful and unique sounds. From the process of the activities carried out, this group was able to produce several pieces of music. The music produced also make the participants feel happy and plan to use the results of this learning for various activities.
\end{abstract}

Keywords: Community Service, use of cultural heritage, Gardner's theory, Pesantian Tambakan-Klaten Sakti Wisnu

\begin{abstract}
Abstrak
Pembelajaran dapat dilakukan oleh siapa pun dan di mana pun. Warisan budaya memberikan alternatif tempat sebagai sumber pembelajaran yang menarik. Hanya saja, tidak banyak orang yang mengerti manfaat yang dapat diperoleh dari warisan budaya. Pengabdian kepada Masyarakat oleh FIB UGM pada 2018 ini melakukan usaha agar masyarakat lebih mengenal sumber pembelajaran dari objek warisan budaya. Objek yang digunakan dalam pembelajaran ini adalah relief tentang orang bermusik yang ada di Candi Borobudur. Pilihan ini didasarkan pada teori Gardner yang menyebutkan bahwa setiap manusia memiliki kecerdasan yang berbeda. Di antara sembilan kecerdasan yang disampaikan oleh Gardner, kecerdasan bermusik menjadi salah satunya. Dengan menerapkaan teori Gardner khususnya kecerdasan bermusik, pengenalan
\end{abstract}


objek relief tentang orang bermusik dari relief Borobudur kepada orang yang menyukai musik diharapkan dapat memudahan mereka untuk menangkap pesan yang disampaikan.

Relief tentang orang bermusik di Candi Borobudur diperkenalkan kepada kelompok pemusik, yaitu kelompok Sanggar Pesantian Wisnu Sakti Tambakan yang berlokasi di Desa Tambakan, Kecamatan Jogonalan, Kabupaten Klaten. Cara yang dilakukan adalah dengan melihat dan menirukan gerakan badan seperti yang ada pada relief orang bermusik di Candi Borobudur. Hasil pengamatan memperlihatkan bahwa peserta merasakan keindahan dari gerakan yang ditunjukkan dan merasakan suara musik yang dihasilkan dengan posisi tangan serta alat yang sesuai sehingga menghasilkan suara yang indah dan unik. Dari proses kegiatan yang dilakukan, kelompok ini mampu menghasilkan beberapa penggalan musik. Musik yang dihasilkan pun membuat peserta merasa senang dan berencana menggunakan hasil pembelajaran ini untuk berbagai kegiatan.

Kata Kunci: Pengabdian kepada Masyarakat, pemanfaatan warisan budaya, teori Gardner, Pesantian Wisnu Sakti Tambakan-Klaten

\section{Pendahuluan}

Candi merupakan salah satu objek destinasi wisata utama. Bus-bus dari berbagai wilayah di Jawa dan kendaraan-kendaraan pribadi terlihat parkir di pelataran parkir Candi Prambanan dan Borobudur. Ribuan orang mengunjungi objek wisata warisan budaya abad VIII hingga X ini. Kegembiraan dan kekaguman tampak dari ekspresi pengunjung, terutama karena ukuran bangunan yang tinggi dan besar. Yang tampak dari pengunjung ketika selesai melihat adalah kelelahan dengan keringat yang bercucuran. Kegiatan yang dilakukan pengunjung adalah naik ke candi dan juga berfoto bersama teman atau keluarga. Pengunjung belum mendapatkan manfaat yang lebih maksimal dari objek warisan budaya yang ada. Padahal, dengan mengunjungi warisan budaya, pengunjung semestinya dapat menghubungkan kondisi saat ini dengan masa lalu. Dengan memahami masa lalu melalui warisan budaya, banyak hal yang dapat dilakukan untuk masa sekarang dan masa yang akan datang. Warisan budaya adalah salah satu alternatif untuk memahami kebudayaan yang dapat dilakukan oleh semua umur dan dengan cara masing-masing.

Objek Warisan Budaya memiliki berbagai keunikan yang dapat digunakan sebagai sarana pembelajaran bagi para pengunjung. Jenis-jenis keunikan yang dapat dimanfaatkan pengunjung harus disampaikan secara bertahap. Proses pembelajaran pada objek warisan budaya tidaklah instan sehingga diperlukan inisiatif dari tiap-tiap individu agar lebih aktif memanfaatkan warisan budaya sebagai sumber ide atau sumber pengetahuan. Tidak hanya transfer pengetahuan dan pemahaman, tetapi juga mengajar keterampilan kreatif dan menikmati pengetahuan dengan keindahan pengetahuan itu. Warisan budaya sebetulnya memberikan alternatif sumber pengayaan ide yang dapat dikembangkan kapanpun dan di manapun serta oleh siapa pun. Oleh karena itu, untuk mengenalkan objek warisan budaya kepada calon pegunjung, perlu dilakukan pengenalan objek-objek yang mampu memberikan gambaran nyata bagi para calon pengunjung tentang manfaat warisan budaya.

Persoalannya, diperlukan sarana yang mampu untuk menjembataninya. Diperlukan orang-orang yang memahami keistimewaan dan keunikan warisan budaya untuk dapat 
disampaikan kepada masyarakat. Sudah sering kali arkeolog dan sejarawan memberikan informasi tersebut. Namun demikian, apakah yang disampaikan itu sesuai dengan minat para pendengarnya? Apakah yang disampaikan itu sesuai dengan jawaban dan pengetahuan yang dibutuhkan oleh masyarakat? Oleh karena itu, kegiatan Pengabdian kepada Masyarakat ini berusaha untuk mengenalkan warisan budaya kepada kelompok tertentu. Pengenalkan objek khusus kepada kelompok khusus ini diharapkan dapat menghasilkan minat dari kelompok lain dalam memahami kekayaaan pengetahuaan dari warisan budaya Indonesia.

Dalam teori Gardner disebutkan bahwa masing-masing individu memiliki kecerdasan khusus. Dapat saja satu individu memiliki lebih dari satu jenis kecerdasan. Gardner menyebutkan bahwa terdapat sembilan macam kecerdasan. Perbedaan kecerdasan inilah yang menyebabkan minat masing-masing pengunjung warisan budaya berbeda satu sama lain. Selama ini, para pemusik atau individu yang menyukai musik menganggap bahwa warisan budaya tidaklah menarik.

Oleh karena itu, dalam kegiatan ini, dilakukan pengenalan warisan budaya kepada kelompok yang suka bermain musik ataupun kelompok yang berminat dengan alat musik. Pada kegiatan pengabdian ini, kelompok yang disasar adalah generasi muda yang gemar dan sedang belajar musik. Dalam sebuah kelompok harus ada peserta yang memiliki latar belakang pendidikan dalam bidang seni atau pernah belajar musik di Institut Seni Indonesia, Yogyakarta dan Solo. Berdasarkan kriteria yang ada, kelompok yang

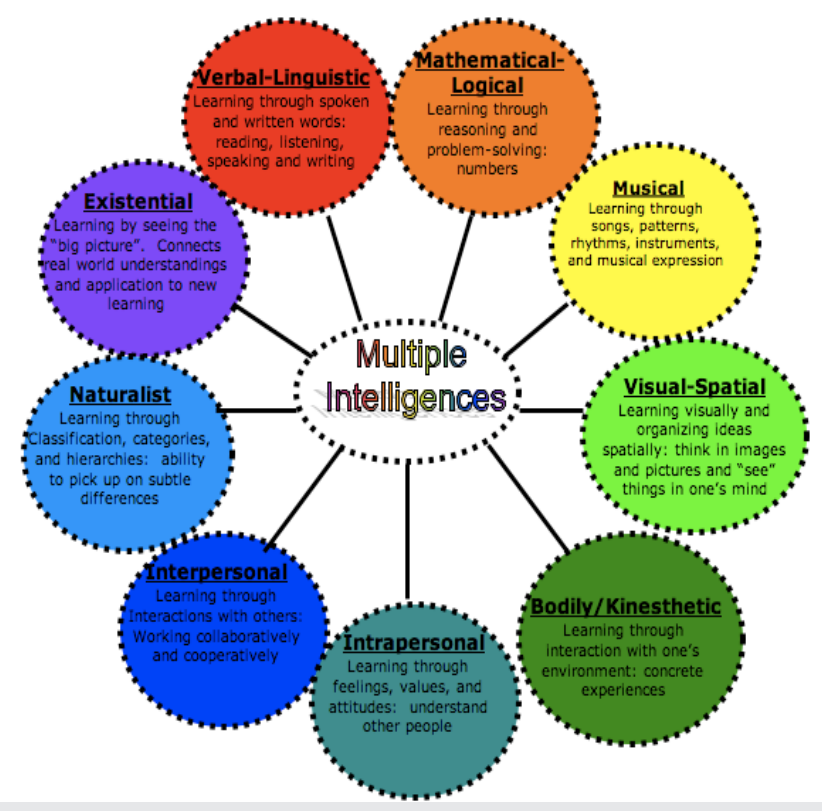

Gambar 1. Sembilan Macam

Kecerdasan pada Teori Gardner dipilih adalah kelompok sanggar Pesantian Wisnu Sakti Tambakan. Kelompok ini adalah kelompok pemuda yang merupakan bagian dari Pura Wisnu Sakti di Desa Tambakan, Kecamatan Jogonalan, Kabupaten Klaten.

Kelompok Pesantian Wisnu Sakti ini merupakan kelompok Pemuda yang sedang belajar untuk mengiringi kegiatan upacara agama Hindu. Peralatan yang biasa digunakan adalah gamelan dan tidak menggunakan alat musik elektronik. Kelompok yang menyukai musik akan diperkenalkan dan diajari mengenai warisan budaya yang dimulai dengan mengenalkan relief orang bermain musik. Dengan cara ini, diharapkan dapat meningkatkan keinginan untuk mengenal, memahami, dan memanfaatkan warisan budaya. 


\section{Metode}

Proses mengenalkan benda cagar budaya sebagai sumber pembelajaran dilakukan dengan cara mengenalkan agar diingat dan dipahamai, menerapkan, menganalisis, mengevaluasi, hingga akhirnya menciptakan karya baru

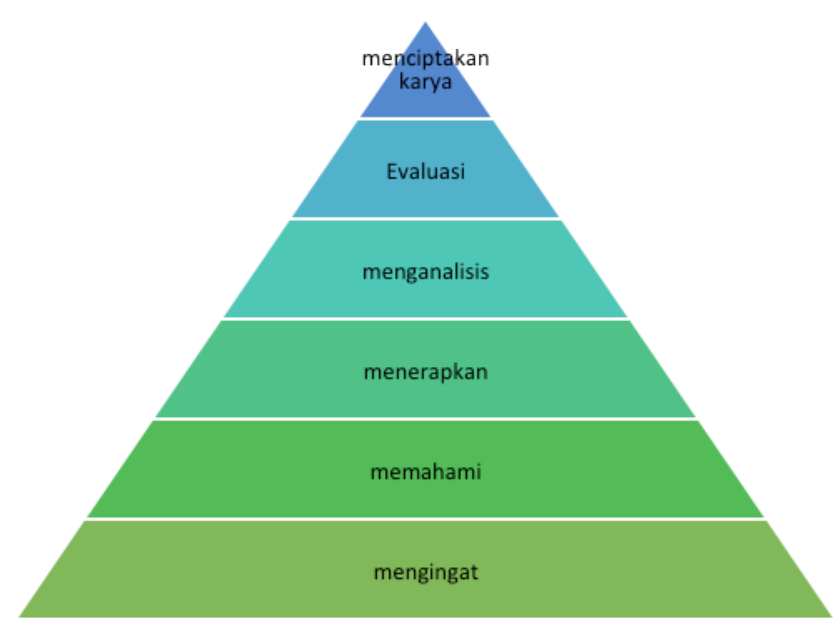

Proses tersebut dilakukan dengan kegiatan Forum Group Discussion (FGD) dan diikuti dengan beberapa pertemuan informal. Pendampingan secara informal dilakukan untuk mengawal proses analisis dan mengevaluasi. Pada tataran proses menciptakan sesuatu yang baru, tidak dilakukan pendampingan agar mereka dapat mengekspresikan proses pembelajarannya secara bebas.

Kelompok ini diajak untuk mengenal dan mengapresiasi relief musik yang ada pada relief di Candi Borobudur. Kelompok tersebut ditawarkan pengalaman khusus untuk melihat, meniru, dan berkreasi atas relief pemusik di relief Candi Borobudur.
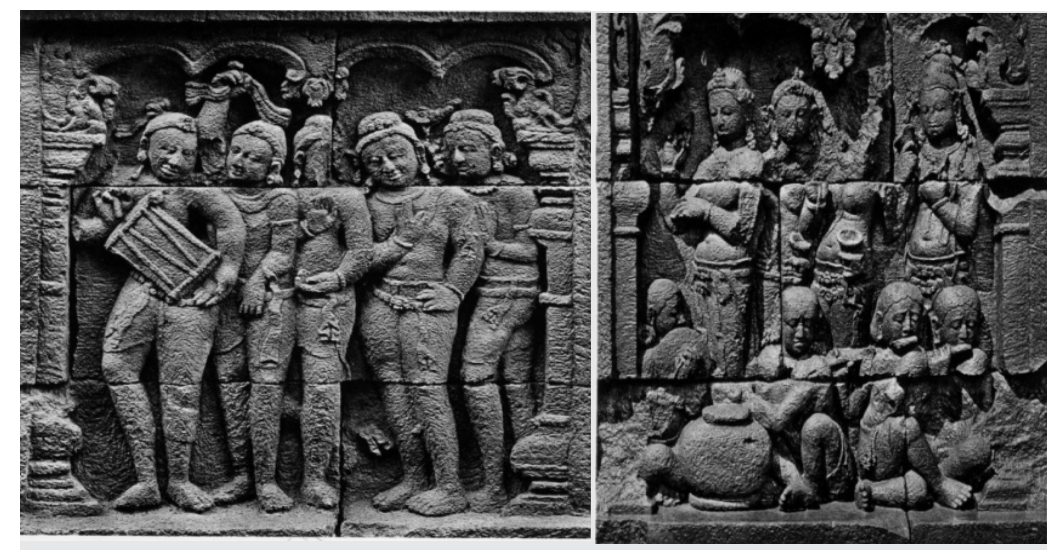

Gambar 2. Relief Orang Bermain Musik dari Candi Borobudur

Metode yang dilakukan adalah mengenalkan adanya pemusik di relief Candi Borobudur. Relief sebagai objek pembelajaran dikenalkan sebagai bahan pelajaran yang menyenangkan, yakni belajar sambil bermain. Bermain dilakukan dengan meniru dan membuat suara. 
Dengan FGD, peserta diajak berpartisipasi aktif untuk mempelajari relief candi, dengan Candi Borobudur yang digunakan sebagai salah satu sumber pembelajaran secara langsung. Secara terencana, pada FGD, yang menjadi sasaran adalah kelompok yang menyukai musik sehingga diharapkan peserta memahami adanya sumber pembelajaran dari relief candi yang bertema alat musik. Kelompok yang menyukai musik diharapkan dapat menemukan sesuatu yang menyenangkan melalui pengalaman melihat dan menirukan seperti yang ada di relief sehingga mereka dapat mengembangakan dirinya dalam bermusik. Konsep yang digunakan dalam kegiatan FGD adalah proses pembentukan pengalaman yang dapat membawa perubahan perilaku pribadi (Singh, 2004:17).

Kegiatan ini dilakukan dengan menyenangkan karena meniru kesamaan cara duduk, kesamaan pakaian, hingga kesamaan dalam menggunakan alat musik. Mengenal warisan budaya, terutama tentang relief orang bermain musik, dilakukan dengan didialogkan. Berdasarkan dialog yang ada, diharapkan mereka dapat mulai tertarik dan merasa antusias. Dari antusiame tersebut, mereka diajak untuk melihat objek secara langsung, yang sebelumnya hanya mereka lihat melalui foto.

Terdapat lebih dari sepuluh relief bergambar pemusik di Candi Borobudur. Mereka akan diajak untuk meningkatkan pemahaman dan apresiasi terhadap warisan budaya masa lampau, khususnya pada tiap relief pemusik di Candi Borobudur. Gerakan yang pernah dicoba ketika FGD kemudian dikembangkan ketika melihat objek secara langsung.

Berdasarkan hasil FGD, para pemusik muda tersebut diharapkan dapat mengulangi gerakan dengan alat yang sama seperti yang ada pada relief. Dari gerakan-gerakan tersebut, mereka diharapkan mulai melakukan beberapa gerakan musikal dan memunculkan nada-nada khusus ciptaan mereka. Berdasarkan workshop yang dilakukan, para pemusik melakukan olah diri dan merefleksi diri atas proses pembelajaran mengenal relief pemusik di Candi Borobudur. Diharapkan pula, para pemusik muda mampu merefleksi diri dan mampu menjadikan pembelajaran tersebut sebagai salah satu pemicu kreasinya. Peserta mampu menemukan manfaat dari pengenalan objek warisan budaya. Dengan melihat objek relief yang sesuai dengan minat mereka, yaitu musik, generasi muda pemusik merasakan proses bermusik dengan pengalamannya bermusik (meaningful experience). Berdasarkan yang mereka lihat dan kembangkan dalam dialog, akan muncul kemampuan memahami kemudian muncul ide-ide yang dapat ditangkap sebagai kreasi bermusiknya.

\section{Tahap Persiapan}

Terdapat beberapa kegiatan yang dilakukan untuk mempersiapkan pelaksanaan Pengabdian kepada Masyarakat ini, di antaranya adalah sebagai berikut.

1. Penyamaan persepsi dan tujuan kegiatan oleh semua anggota tim.

- setiap anggota belajar memahami isi relief tentang musik

- melakukan diskusi atas apa yang dipahami

- membuat persiapan untuk bahan FGD

2. Melakukan kontak dengan beberapa kelompok pemusik yang berlatar belakang mahasiswa Institut Seni Indonesia, baik yang ada di Yogyakarta maupun di 
Surakarta.

3. Memilih kelompok yang menjadi target.

4. Melakukan komunikasi dan melakukan perencanaan pelaksanaan kegiatan.

\section{Hasil Kegiatan}

Kegiatan pengenalan objek relief orang bermusik di Candi Borobudur dikenalkan kepada kelompok pemusik dan anggota kelompok keagamaan Hindu. Kelompok pemusik ini merupakan bagian dari kelompok pemuda Hindu yang tergabung di Pura Wisnu Sakti di Desa Tambakan, Kecamatan Jogonalan, Kabupaten Klaten, Jawa Tengah. Untuk membuat kelompok target tertarik dengan relief di Candi Borobudur yang bercorak agama Buddha, maka dikenalkan terlebih dahulu tentang candi-candi Hindu di sekitar permukiman mereka. Kelompok ini sering melakukan ibadah di Candi Prambanan. Oleh karena itu, pembahasan tentang keunikan candi lebih ditekankan pada Candi Prambanan.

Berdasarkan hasil diskusi yang berkembang dalam FGD, dapat ditarik kesimpulan bahwa peserta FGD kurang mengenali tempat ibadahnya. Peserta FGD hafal dan mengerti tentang dewa-dewa, bangunan, serta relief Ramayana yang ada. Akan tetapi, pemahaman lebih terhadap masing-masing relief dan keunikan Candi Prambanan belum diketahui oleh mereka.

Oleh karena itu, dalam diskusi dilakukan pengenalan keunikan Candi Prambanan. Dalam diskusi ditunjukkan data tentang titik pusat Candi Prambanan, seperti relief bidadari yang ada pada bagian badan Candi Prambanan. Mereka pun sangat antusias menggali hal-hal mengenai tempat ibadah mereka. Antusiasme tersebut sangat penting bagi pelatihan ini karena dapat menjadi indikator ketertarikan peserta untuk melakukan pembelajaran lebih lanjut. Dalam kondisi ini, dapat ditengarai bahwa tahapan pembelajaran memahami sudah tersampaikan dan diaplikasikan oleh peserta FGD.

Antusiasme peserta FGD dikembangkan lebih lanjut. Ketika peserta diminta menirukan pose para bidadari pada relief Candi Prambanan, mereka melakukannya dengan serentak dan gembira. Pada mulanya mereka malu-malu, tetapi kemudian tersenyum bahagia. Kegiatan peniruan ini berhasil dilakukan sehingga tahapan pembelajaran penerapan dapat dilaksanakan dengan baik.

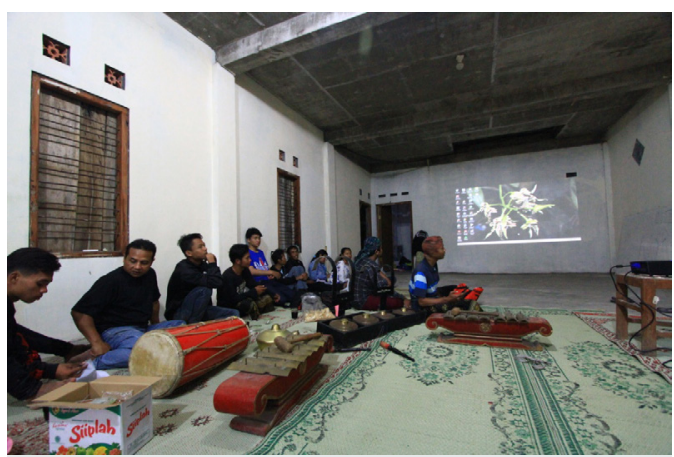

Foto 1. Sebagian Peserta FGD

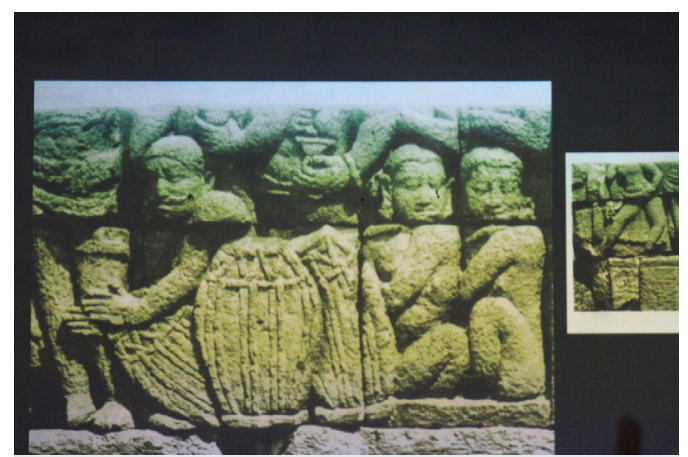

Foto 2. Salah Satu Relief Orang Bermusik pada Relief Candi Borobudur 


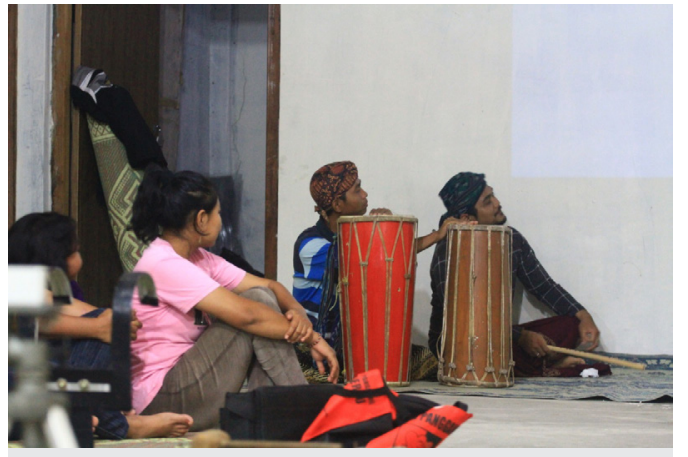

Foto 3. Peserta FGD

Memperhatikan Presentasi

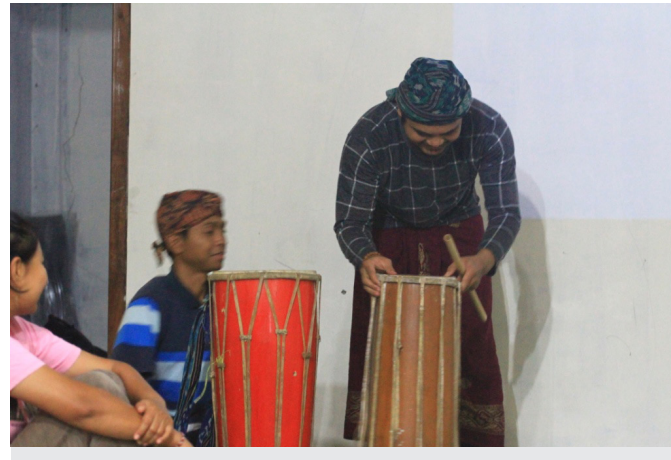

Foto 4. Peserta FGD Berusaha Mencontoh Posisi Alat Musiknya Seperti yang Ada pada Relief

Proses analisis dikenalkan dalam proses pembelajaran ini. Motivator FGD menyampaikan bahwa berbagai gerakan tersebut bila disambungkan dapat menjadi satu gerakan tarian. Kemudian, peserta secara spontan menyampaikan akan menggunakan gerakan itu untuk acara peringatan kemerdekaan 17 Agustus yang akan datang. Dari proses FGD ini diperoleh gambaran jelas bahwa para peserta mampu menemukan manfaat pengenalan objek warisan budaya di sekitar mereka. Mereka berharap ketika mengunjungi candi untuk beribadah, mereka akan lebih memperhatikan dan menikmati serta mempelajari objek warisan budaya yang ada di sekitar mereka.

Ketika objek yang ditirukan berpindah dari Candi Prambanan ke relief Candi Borobudur, peserta FGD merasakan manfaat pengetahuan yang diperoleh sebelumnya, sehingga dengan antusiasme mereka dapat mempelajari objek yang berbeda tanpa merasa kesulitan. Relief pada Candi Borobudur merupakan objek utama dari kegiatan pengabdian ini. Relief di Borobudur hanya digunakan sebagai sarana menarik peserta FGD. Tidak ada tambahan informasi tentang ceritera isi relief, karena kegiatan ini hanya sebagai pemantik peserta FGD mengenal relief orang bermusik pada masa lalu. Dalam kegiatan FGD, peserta diminta untuk menirukan gerakan kaki dan badan para pemain musik. Oleh karena sebelumnya mereka sudah melakukan peniruan untuk gerakan tari, maka pada kegiatan menirukan gerak pemusik di relief Candi Borobudur pun dapat dilakukan lebih mudah.

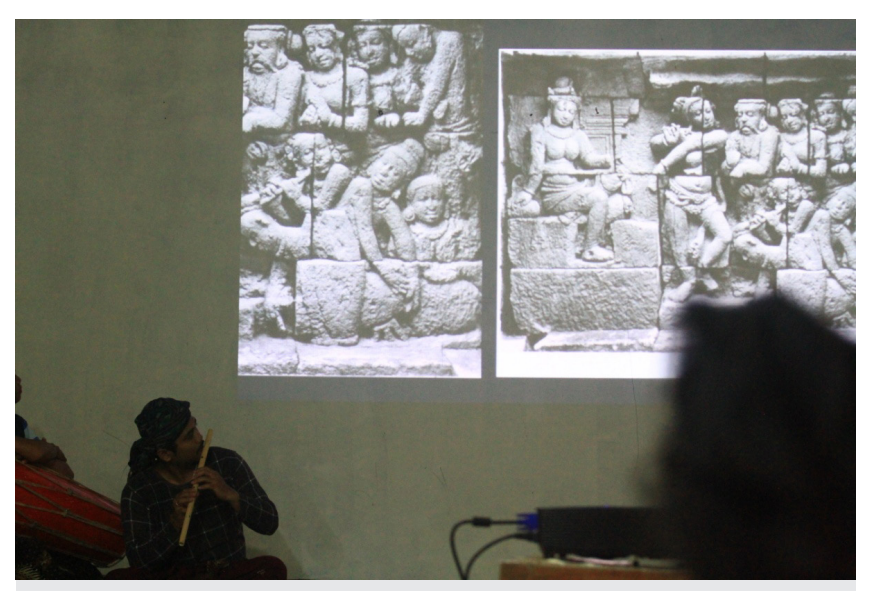

Foto 5. Peserta Mencoba Meniru Posisi Duduk dan Cara Memegang Alat Tiup Seruling Seperti yang Ada pada Relief 
Peserta secara cepat menirukan gerakan yang ada pada relief Candi Borobudur, yaitu gerakan pemusik dengan alat-alat musiknya. Peserta secara serentak meminta salah seorang peserta untuk mengambil kendang, gamelan, dan suling yang mereka punyai. Secara sigap dan bersamaan, mereka melakukan gerakan membunyikan alatalat musik yang ada.

Dalam waktu singkat, para peserta melakukan penyesuaian diri dengan posisi duduk, posisi tangan, dan posisi alat musiknya. Kemudian, mereka membunyikan alat-alatnya secara ritmis. Musik yang dimainkan berkaitan dengan kebiasaan mereka melakukan upacara keagamaan. Namun demikian, mereka mengembangkannya lebih lanjut karena menyadari bahwa dengan posisi tersebut, bunyi yang dihasilkan memiliki suara yang berbeda.

Antusiasme pemusik terlihat saat memainkan atau mengkreasikan 'suara' untuk menjadi musik yang sesuai dengan keindahannya. Beberapa kali mereka mendengar rekaman atas musik yang dihasilkan dari meniru posisi seperti relief. Sambil tertawa, mereka melakukan evaluasi diri. Setelah mencoba beberapa kali, mereka melakukan koordinasi sederhana.

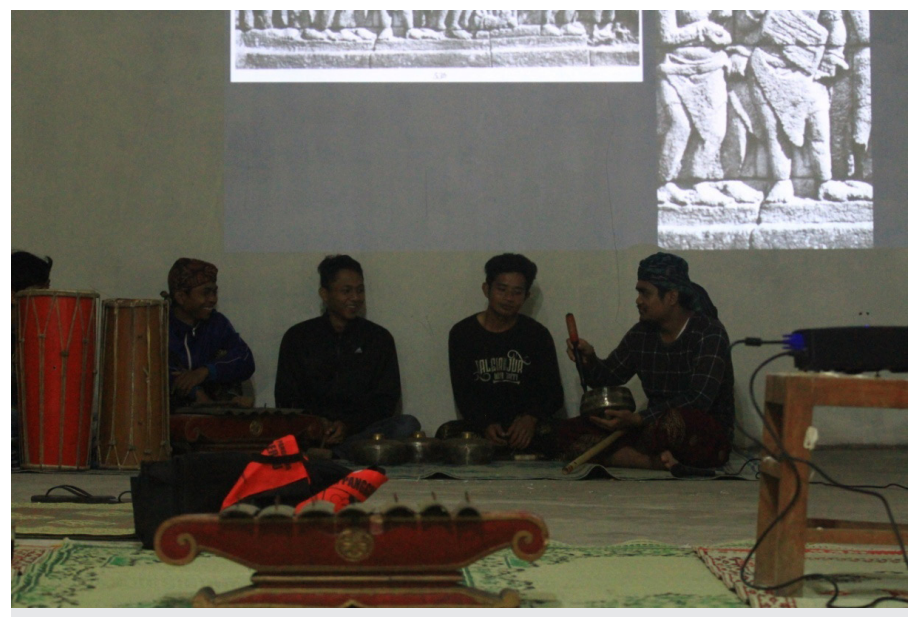

Foto 6. Peserta FGD Mendiskusikan Bentuk Ketukan Musik Proses evaluasi dalam pembelajaran ini dilakukan. Peserta FGD melakukan dengan senang--mereka sambil tertawa bahagia. Setelahnya, mereka pun mampu menghasilkan musik yang lebih baik menurut peserta lainnya.

Hasil FGD kemudian diendapkan oleh para pemain musik di FGD. Setelah seminggu, dengan melakukan latihan beberapa kali, para pemusik mampu menginterpretasikan dan mengembangkan ekspresi kelompok dan menghasilkan musik yang menurut mereka sesuai, baik, dan indah. Kreatifitas dan inovasi mereka sangat diwarnai dengan pengetahuan mereka yang dipunyai sebelumnya. Nilai (value) adalah hal yang sangat subjektif, namun dalam pembelajaran, subjek secara bebas dapat menentukan kepuasan atas hasil kerja kerasnya.

Hasil akhir dari bermain musik dengan meniru posisi duduk dan memegang peralatan musik seperti pada relief Candi Borobudur adalah jingle musik yang sesuai dengan kebutuhan kelompok ini. Musik yang dihasilkan adalah simbol atas kelompoknya. Hasil musik yang dibuat oleh peserta FGD ini rencananya akan digunakan untuk:

1. mengiringi Ogoh-ogoh yang dibuat oleh Sanggar Pesantian Wisnu Sakti Tambakan pada Perayaan 17 Agustus di Klaten,

2. mengiringi kegiatan Galungan pada November 2018,

3. acara Pentas Budaya tahun 2019 dengan tema The Sound of Prambanan. 
Selama proses pembelajaran warisan budaya pada kelompok Sanggar Pesantian Wisnu Sakti Tambakan, tidak semua peserta memperoleh pembelajaran yang sama. Sebagian hanya berhenti hingga proses menerapkan dengan menirukan objek. Namun demikian, ada pula beberapa orang yang melanjutkan hingga proses menciptakan musik. Bagian yang menarik adalah kelompok ini saling membantu hingga kelompok pencipta musik selesai melakukan rekaman atas ciptaannya. Hasil yang tidak sama pada tiap peserta adalah hal yang biasa. Namun demikian, keikutsertaan mereka secara bersama-sama dapat mendukung anggota yang lain dan menunjukkan minat mereka untuk belajar proses pembentukan diri.

Di Sanggar Pesantian Wisnu Sakti, Desa Tambakan, Kecamatan Jogonalan, Kabupaten Klaten, peserta FGD merasakan bahwa terdapat tambahan pemahaman atas tinggalan masa lampau yang semakin meningkat, diantaranya:

1. Merasakan proses pembelajaran berupa pengalaman belajar tentang heritage. Kelompok ini paham bahwa heritage di sekitarnya menyediakan alternatif sumber pembelajaran.

2. Relief bermusik mampu mendorong kelompok musik melakukan inovasinya dalam bermusik. Para pemusik memiliki tambahan pengetahuan tentang kebudayaan lokal sehingga mampu bersaing di kancah internasional.

3. Masyarakat memahami cara untuk mendapatkan objek kreasi dan inovasi selain menggunakan gawai, mengunjungi perpustakaan, arsip, dan sebagainya.

Peserta dalam kegiatan pengabdian ini sebagian besar masuk dalam katagori explorer dan experience seeker bila menggunakan model yang dilakukan oleh Falk (2009). Namun demikian, ada satu peserta yang menjadi motor dari penciptaan musik ini. Beliau adalah alumni ISI Surakarta yang sedang melakukan studi di UNS. Dalam kelompok peserta pengabdian, beliau melakukan recharger atas pengalamannya bermusik dengan seruling. Keberadaan beliau menjadi penting dalam kegiatan ini karena membuat peserta lain menjadi lebih tertarik dan mengenal warisan budaya.

\section{Penutup}

Berdasarkan hasil Pengabdian kepada Masyarakat, yakni mengenalkan relief orang bermusik yang ada pada relief Candi Borobudur, mampu mengubah pandangan masyarakat secara positif terhadap warisan budaya. Warisan budaya bukan hanya menjadi objek foto yang dimuat di instagram dan media sosial, melainkan juga menjadi sumber inspirasi. Behavioral intentions muncul pada beberapa individu peserta FGD. Dua pekan setelah kegiatan berakhir, satu peserta yang memiliki minat menggambar tertarik untuk membuat komik yang bersumber dari obek warisan budaya tersebut. Mengenalkan objek warisan budaya memang tidak dapat secara instan dan menghasilkan jumlah yang banyak. Namun demikian, proses pengenalan dengan kegiatan Pengabdian kepda Masyarakat tersebut dapat digunakan pada kelompok lain dengan topik yang berbeda. Secara jelas, dapat dirasakan bahwa masyarakat memerlukan bantuan dari para akademisi untuk lebih mengenali sejarah warisan budaya di sekitarnya. 


\section{Daftar Pustaka}

Falk, John H. 2009. Identity and the Museum Visitor Experience. Walnut Creek, CA: Left Coast Press.

Gardner, Howard. 2003. Kecerdasan Majemuk. (Terj. Alexander Sindoro, Ed. Lyndon Saputra). Batam: Interaksara.

Hooper-Greenhill, Eilean, Museum and Education: Purpose, Pedagogy, Performance, London: Routledge

Lipe, William D. 2009. "Archaeological Value and esource Management" dalam Archaeology and Cultural Resource Management, school for Advanced Research Press. Pp. 41-64.

Merriaam, Alan P. 1980. The Anthropology of Music. Northwestern University Press.

Pearce, Susan. 1995. "Collection as medium and message" dalam Museum, Media, Message. London: Routledge, pp. 14-22.

Singh, Prabhas Kumar. 2004. "Museum and Education" dalam OHRJ Vol. XLVII, No. 1, hlm. 69-82. 